\title{
Cubic B-Spline Collocation Method for Sixth Order Boundary Value Problems
}

\author{
Y. Showri Raju \\ Associate Professor \\ Department of Computational Sciences \\ College of Natural and Computational Sciences \\ Wollega University, Nekemte, Ethiopia
}

\begin{abstract}
*Corresponding Author: Y. Showri Raju, Associate Professor, Department of Computational Sciences, College of Natural and Computational Sciences, Wollega University, Nekemte, Ethiopia
\end{abstract}

\begin{abstract}
A finite element method involving collocation method with Cubic B-splines as basis functions have been developed to solve sixth order boundary value problems. The third order, fourth order, fifth order and sixth order derivatives for the dependent variable are approximated by the central differences of second order derivatives. The basis functions are redefined into a new set of basis functions which in number match with the number of collocated points selected in the space variable domain. The proposed method is tested on six linear and five non-linear boundary value problems. The solution of a non-linear boundary value problem has been obtained as the limit of a sequence of solutions of linear boundary value problems generated by quasi-linearization technique. Numerical results obtained by the present method are in good agreement with the exact solutions available in the literature.
\end{abstract}

Keywords: collocation method; cubic B-spline; basis function; sixth order boundary value problem; absolute error.

\section{INTRODUCTION}

In this paper, we developed a collocation method with cubic B-splines as basis functions for getting the numerical solution of a general linear sixth order boundary value problem, which is in the form

$a_{0}(x) y^{(6)}(x)+a_{1}(x) y^{(5)}(x)+a_{2}(x) y^{(4)}(x)+a_{3}(x) y^{\prime \prime \prime}(x)+a_{4}(x) y^{\prime \prime}(x)+a_{5}(x) y^{\prime}(x)+a_{6}(x) y(x)=$

$b(x), \quad c<x<d$

subject to the boundary conditions

$y(c)=A_{0}, y(d)=B_{0}, y^{\prime}(c)=A_{1}, y^{\prime}(\mathrm{d})=B_{1}, y^{\prime \prime}(c)=A_{2}, \quad y^{\prime \prime}(\mathrm{d})=B_{2}$.

where $A_{0}, B_{0}, A_{1}, B_{1}, A_{2}, B_{2}$ are finite real constants $a_{0}(x), a_{1}(x), a_{2}(x), a_{3}(x), a_{4}(x), a_{5}(x)$,

$a_{6}(x)$ and $b(x)$ are all continuous functions defined on the interval $[c, d]$.

Generally, these types of differential equations have special significance in astrophysics. The dynamo action in some stars may be modelled by sixth order boundary value problems[1].

The narrow convecting layers bounded by stable layers, which are believed to surround A-type stars, may be modelled by sixth-order boundary value problems[2]. Moreover, when an infinite horizontal layer of fluid is heated from below and is subjected to the action of rotation, instability sets in. When this instability is an ordinary convection, the ordinary differential equation is a sixth-order ordinary differential equation. For further discussion of sixth-order boundary value problems, see[3,4,5].

The existence and uniqueness of solution of such type of boundary value problems can be found in the book written by Agarwal [6] . El-Gamel et al.[7] used Sinc-Galerkin method to solve sixth order boundary value problems. Akram and Siddiqi[8] solved the boundary value problem of type (1)-(2) with non-polynomial spline technique. Siddiqi et al. [9] solved the same boundary value problems using quintic splines. Also Siddiqi and Akram[10] used septic splines to solve the boundary value 
problems of type (1)-(2). Lamini et al.[11] used spline collocation method to solve the sixth-order boundary value problems.

Further, decomposition methods [12], Ritz's method based on the variational theory [13], and the homotopy perturbation method [14] have been applied for the solution of sixth-order boundary value problems. Variational iteration method for solving sixth-order boundary value problems have been developed by Noor et al. [15]. Siraj-ul-Islam et al. [16,17] developed non-polynomial splines approach to the solution of sixth-order and fourth-order boundary-value problems. Viswanadham et al. $[18,19]$ used sixth order and septic B-splines to solve sixth order boundary value problems.

The above studies are concerned to solve sixth order boundary value problems by using quintic or sextic or septic B-splines. In this paper, cubic B-splines as basis functions have been used to solve the boundary value problems of the type (1)-(2).

In section 2 of this paper, the justification for using the collocation method has been mentioned. In section 3, the definition of cubic B-splines has been described. In section 4, description of the collocation method with cubic B-splines as basis functions has been presented and in section 5, solution procedure to find the nodal parameters is presented. In section 6, numerical examples of both linear and non-linear boundary value problems are presented. The solution of a nonlinear boundary value problem has been obtained as the limit of a sequence of solutions of linear boundary value problems generated by quasi-linearization technique [20]. Finally, the last section is dealt with conclusions of the paper.

\section{JUSTIFICATION FOR USING COLLOCATION METHOD}

In finite element method (FEM) the approximate solution can be written as a linear combination of basis functions which constitute a basis for the approximation space under consideration. FEM involves variational methods such as Ritz's approach, Galerkin's approach, least squares method and collocation method etc. The collocation method seeks an approximate solution by requiring the residual of the differential equation to be identically zero at $\mathrm{N}$ selected points in the given space variable domain where $\mathrm{N}$ is the number of basis functions in the basis [21]. That means, to get an accurate solution by the collocation method, one needs a set of basis functions which in number match with the number of collocation points selected in the given space variable domain. Further, the collocation method is the easiest to implement among the variational methods of FEM. When a differential equation is approximated by $m^{\text {th }}$ order B-splines, it yields $(m+1)^{t h}$ order accurate results [22]. Hence this motivated us to use the collocation method to solve a sixth order boundary value problem of type (1) - (2) with cubic B-splines.

\section{DEFINITION OF CUBIC B-SPLINES}

The existence of the cubic spline interpolate $\mathrm{s}(\mathrm{x})$ to a function in a closed interval $[\mathrm{c}, \mathrm{d}]$ for spaced knots (need not be evenly spaced) $\mathrm{a}=\mathrm{x}_{0}<\mathrm{x}_{1}<\mathrm{x}_{2}<\ldots \ldots .<\mathrm{x}_{\mathrm{n}-1}<\mathrm{x}_{\mathrm{n}}=\mathrm{b}$ is established by constructing it. The construction of $\mathrm{s}(\mathrm{x})$ is done with the help of the cubic B-Splines. Introduce six additional knots $x_{-3}, x_{-2}, x_{-1}, x_{n+1}, x_{n+2}$ and $x_{n+3}$ such that $x_{-3}<x_{-2}<x_{-1}<x_{0}$ and $x_{n}<x_{n+1}<$ $x_{n+2}<x_{n+3}$.

Now the cubic B-splines, given in Cox[23] and Boor[24], are defined by

$B_{i}(x)=\left\{\begin{array}{cl}\sum_{r=i-2}^{i+2} \frac{\left(x_{r}-x\right)_{+}^{3}}{\pi^{\prime}\left(x_{r}\right)}, & x \in\left[x_{i-2}, x_{i+2}\right] \\ 0, & \text { otherwise }\end{array}\right.$

Where

$$
\left(x_{r}-x\right)_{+}^{3}= \begin{cases}\left(x_{r}-x\right)^{3}, & \text { if } x_{r} \geq x \\ 0, & \text { if } x_{r} \leq x\end{cases}
$$

and

$$
\pi(x)=\prod_{r=i-2}^{i+2}\left(x-x_{r}\right) .
$$

It can be shown that the set $\left\{B_{-1}(x), B_{0}(x), \cdots, B_{n}(x), B_{n+1}(x)\right\}$ forms a basis for the space $S_{3}(\pi)$ of cubic polynomial splines[22]. Schoenberg[25] has proved that the cubic B-splines are the unique nonzero splines of smallest compact support with knots at 
$x_{-3}<x_{-2}<x_{-1}<x_{0}<\cdots<x_{n}<x_{n+1}<x_{n+2}<x_{n+3}$.

\section{DESCRIPTION OF THE METHOD}

To solve the boundary value problem (1)-(2) by the collocation method with cubic B-splines as basis functions, we define the approximation for $\mathrm{y}(\mathrm{x})$ as

$$
y(x)=\sum_{j=-1}^{n+1} \alpha_{j} B_{j}(x)
$$

where $\alpha_{j}$ 's are the nodal parameters to be determined. In the present method, the internal mesh points $\mathrm{x}_{2}, \mathrm{x}_{3}, \ldots, \mathrm{x}_{\mathrm{n}-2}$ are selected as the collocation points. In collocation method, the number of basis functions in the approximation should match with the number of selected collocation points [21]. Here the number of basis functions in the approximation (3) is $n+3$, where as the number of selected collocation points is n-3. So, there is a need to redefine the basis functions into a new set of basis functions which in number match with the number of selected collocation points. The procedure for redefining the basis functions is as follows:

Using the cubic B-splines described in section 3 and the Dirichlet boundary conditions of (2), we get the approximate solution at the boundary points as

$$
\begin{array}{r}
y(c)=y\left(x_{0}\right)=\sum_{j=-1}^{1} \alpha_{j} B_{j}\left(x_{0}\right)=A_{0} \\
y(d)=y\left(x_{n}\right)=\sum_{j=n-1}^{n+1} \alpha_{j} B_{j}\left(x_{n}\right)=B_{0} .
\end{array}
$$

Eliminating $\alpha_{-1}$ and $\alpha_{n+1}$ from the equations (3), (4), and(5), we get the approximation for $y(x)$ as

$$
y(x)=w_{1}(x)+\sum_{j=0}^{n} \alpha_{j} P_{j}(x)
$$

where

$$
w_{1}(x)=\frac{A_{0}}{B_{-1}\left(x_{0}\right)} B_{-1}(x)+\frac{B_{0}}{B_{n+1}\left(x_{n}\right)} B_{n+1}(x)
$$

and

$$
P_{j}(x)=\left\{\begin{array}{cl}
B_{j}(x)-\frac{B_{j}\left(x_{0}\right)}{B_{-1}\left(x_{0}\right)} B_{-1}(x), & \text { for } \mathrm{j}=0,1 \\
B_{j}(x), & \text { for } \mathrm{j}=2,3, \ldots, n-2 \\
B_{j}(x)-\frac{B_{j}\left(x_{n}\right)}{B_{n+1}\left(x_{n}\right)} B_{n+1}(x), & \text { for } \mathrm{j}=n-1, n .
\end{array}\right.
$$

Using the Neumann boundary conditions of (2) to the approximate solution $y(x)$ in (6), we get

$$
\begin{aligned}
& y^{\prime \prime}(c)=y^{\circ}\left(x_{0}\right)=w_{1}^{\prime}\left(x_{0}\right)+\alpha_{0} P_{0}^{\circ}\left(x_{0}\right)+\alpha_{1} P_{1}^{\prime}\left(x_{0}\right)=A_{1} \\
& y^{\prime \prime}(d)=y^{\prime \prime}\left(x_{n}\right)=w_{1}^{\circ}\left(x_{n}\right)+\alpha_{n-1} P_{n-1}^{\prime}\left(x_{n}\right)+\alpha_{n} P_{n}^{\prime \prime}\left(x_{n}\right)=B_{1} .
\end{aligned}
$$

Now, eliminating $\alpha_{0}$ and $\alpha_{n}$ from the equations (6), (7) and(8), we get the approximation for $y(x)$ as

$y(x)=w_{2}(x)+\sum_{j=1}^{n-1} \alpha_{j} Q_{j}(x)$

where

$$
w_{2}(x)=w_{1}(x)+\frac{A_{1}-w_{1}^{o}\left(x_{0}\right)}{p_{0}^{s}\left(x_{0}\right)} P_{0}(x)+\frac{B_{1}-w_{1}^{o}\left(x_{n}\right)}{P_{n}^{s}\left(x_{n}\right)} P_{n}(x)
$$

and 
$Q_{j}(x)=\left\{\begin{array}{cc}P_{j}(x)-\frac{P_{j}^{p}\left(x_{0}\right)}{P_{0}^{s}\left(x_{0}\right)} P_{0}(x), \quad \text { for } \quad \mathrm{j}=1 \\ P_{j}(x), \quad \text { for } \mathrm{j}=2,3, \ldots, n-2 \\ P_{j}(x)-\frac{P_{j}^{s}\left(x_{n}\right)}{P_{n}^{s}\left(x_{n}\right)} P_{n}(x), \quad \text { for } \mathrm{j}=n-1 .\end{array}\right.$

Using the boundary conditions $y^{\prime \prime}(c)=A_{2}$ and $y^{\prime \prime}(d)=B_{2}$ of (2) to the approximate solution $y(x)$ in (9), we get

$$
\begin{aligned}
& y^{\prime \prime}(c)=y^{\prime \prime}\left(x_{0}\right)=w_{2}^{\prime \prime}\left(x_{0}\right)+\alpha_{1} Q_{1}^{\prime \prime}\left(x_{0}\right)=A_{2} \\
& y^{\prime \prime}(d)=y^{\prime \prime}\left(x_{n}\right)=w_{2}^{\prime \prime}\left(x_{n}\right)+\alpha_{n-1} Q_{n-1}^{\infty}\left(x_{n}\right)=B_{2} .
\end{aligned}
$$

Now, eliminating $\alpha_{1}$ and $\alpha_{\mathrm{n}-1}$ from the equations (9),(10) and (11), we get the approximation for $\mathrm{y}(\mathrm{x})$ as

$$
y(x)=w(x)+\sum_{j=2}^{n-2} \alpha_{j} \tilde{B}_{j}(x)
$$

where

$$
w(x)=w_{2}(x)+\frac{A_{2}-w_{2}^{w}\left(x_{0}\right)}{Q_{1}^{w}\left(x_{0}\right)} Q_{1}(x)+\frac{B_{2}-w_{2}^{w}\left(x_{n}\right)}{Q_{n-1}^{s}\left(x_{n}\right)} Q_{n-1}(x)
$$

and $\widetilde{B}_{j}(x)=Q_{j}(x)$, for $\mathrm{j}=2,3, \ldots, \mathrm{n}-2$.

Now the new basis functions for the approximation $y(x) \operatorname{are}\left\{\widetilde{B_{j}}(x), j=2,3, \ldots, n-2\right\}$ and they are in number matching with the number of selected collocated points. Since the approximation for $y(x)$ in (12) is a cubic approximation, let us approximate $y^{m \prime}, y^{(4)}{ }_{3} y^{(5)}$ and $y^{(6)}$ at the selected collocated points with central differences as

$$
\begin{aligned}
& y_{i}^{n n}=\frac{y_{i+1}^{n g}-y_{(i-1)}^{n f}}{2 h} \\
& y_{i}^{(4)}=\frac{y_{(i+1)}^{E g}-2 y_{i}^{E g}+y_{(i-1)}^{E g}}{h^{2}} \\
& y_{i}^{(5)}=\frac{y_{(i+2)}^{s i}-2 y_{i+1}^{s s}+2 y_{(i-1)}^{s z}-y_{(i-2)}^{s i}}{2 h^{s}} \\
& y_{i}^{(6)}=\frac{y_{(i+2)}^{s g}-4 y_{i+1}^{s s}+6 y_{(i)}^{s g}-4 y_{i-1}^{s s}+Y_{(i-2)}^{s g}}{h^{4}} \text { for } \mathrm{j}=2,3, \ldots, \mathrm{n}-2
\end{aligned}
$$

where

$$
y_{i}=y\left(x_{i}\right)=w\left(x_{i}\right)+\sum_{j=2}^{n-2} \alpha_{j} \widetilde{B}_{j}\left(x_{i}\right) .
$$

Now applying collocation method to (1), we get

$$
\begin{aligned}
& a_{0}\left(x_{i}\right) y_{i}^{(6)}+a_{1}\left(x_{i}\right) y_{i}^{(5)}+a_{2}\left(x_{i}\right) y_{i}^{(4)}+a_{3}\left(x_{i}\right) y_{i}^{\prime \prime \prime} \\
& +a_{4}\left(x_{i}\right) y_{i}^{\prime \prime}+a_{5}\left(x_{i}\right) y_{i}^{\prime}+a_{6}\left(x_{i}\right) y_{i}=b\left(x_{i}\right) \text { for } \mathrm{i}=2,3, \ldots, \mathrm{n}-2 .
\end{aligned}
$$

Using (13) and (14) in (15), we get

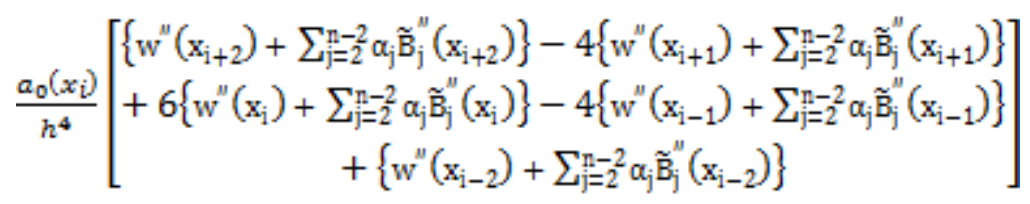




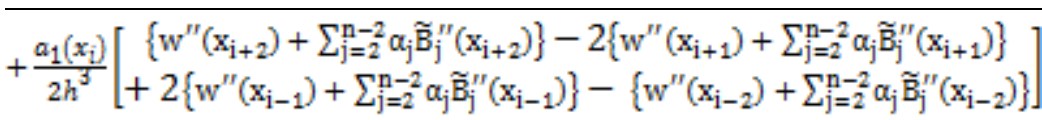

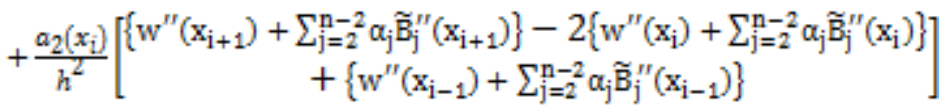

$+\frac{a_{3}\left(x_{i}\right)}{2 h}\left[\left\{w^{n s}\left(\mathrm{x}_{\mathrm{i}+1}\right)+\sum_{\mathrm{j}=2}^{\mathrm{n}-2} \alpha_{\mathrm{j}} \tilde{\mathrm{B}}_{\mathrm{j}}^{(s)}\left(\mathrm{x}_{\mathrm{i}+1}\right)\right\}-\left\{\mathrm{w}^{t s}\left(\mathrm{x}_{\mathrm{i}-1}\right)+\sum_{\mathrm{j}=2}^{\mathrm{n}-2} \alpha_{\mathrm{j}} \widetilde{\mathrm{B}}_{\mathrm{j}}^{t s}\left(\mathrm{x}_{\mathrm{i}-1}\right)\right\}\right]$

$+\mathrm{a}_{4}\left(\mathrm{x}_{\mathrm{i}}\right)\left[\mathrm{w}^{\prime \prime}\left(\mathrm{x}_{\mathrm{i}}\right)+\sum_{\mathrm{j}=2}^{\mathrm{n}-2} \alpha_{\mathrm{j}} \widetilde{\mathrm{B}}_{\mathrm{j}}^{\prime \prime}\left(\mathrm{x}_{\mathrm{i}}\right)\right]+\mathrm{a}_{5}\left(\mathrm{x}_{\mathrm{i}}\right)\left[\mathrm{w}^{\prime}\left(\mathrm{x}_{\mathrm{i}}\right)+\sum_{\mathrm{j}=2}^{\mathrm{n}-2} \alpha_{\mathrm{j}} \widetilde{\mathrm{B}}_{\mathrm{j}}^{\prime}\left(\mathrm{x}_{\mathrm{i}}\right)\right]$

$+a_{6}\left(x_{i}\right)\left[w\left(x_{i}\right)+\sum_{j=2}^{n-2} \alpha_{j} \widetilde{B}_{j}\left(x_{i}\right)\right]=b\left(x_{i}\right) \quad$ for $\quad \mathrm{i}=2,3, \ldots, \mathrm{n}-2$.

Rearranging the terms and writing the system of equations(16) in the matrix form, we get $\mathrm{A} \alpha=\mathrm{B}$

where $A=\left[\mathrm{a}_{\mathrm{ij}}\right]$;

$a_{i j}=\widetilde{B}_{j}^{\prime \prime}\left(x_{i-2}\right)\left(\frac{a_{0}\left(x_{i}\right)}{h^{4}}-\frac{a_{1}\left(x_{i}\right)}{2 h^{s}}\right)+\widetilde{B}_{j}^{\prime \prime}\left(x_{i-1}\right)\left(-4 \frac{a_{0}\left(x_{i}\right)}{h^{4}}+2 \frac{a_{1}\left(x_{i}\right)}{2 h^{3}}+\frac{a_{2}\left(x_{i}\right)}{h^{2}}-\frac{a_{g}\left(x_{i}\right)}{2 h}\right)$

$+\widetilde{\mathrm{B}}_{\mathrm{j}}^{\prime \prime}\left(\mathrm{x}_{\mathrm{i}}\right)\left(6 \frac{\mathrm{a}_{0}\left(\mathrm{x}_{\mathrm{i}}\right)}{\mathrm{h}^{4}}-2 \frac{\mathrm{a}_{\mathrm{z}}\left(\mathrm{x}_{\mathrm{i}}\right)}{\mathrm{h}^{2}}\right)+\widetilde{\mathrm{B}}_{\mathrm{j}}^{\prime \prime}\left(\mathrm{x}_{\mathrm{i}+1}\right)\left(-4 \frac{\mathrm{a}_{0}\left(\mathrm{x}_{\mathrm{i}}\right)}{\mathrm{h}^{4}}-2 \frac{\mathrm{a}_{1}\left(\mathrm{x}_{\mathrm{i}}\right)}{2 \mathrm{~h}^{\mathrm{s}}}+\frac{\mathrm{a}_{\mathrm{z}}\left(\mathrm{x}_{\mathrm{i}}\right)}{\mathrm{h}^{\mathrm{2}}}+\frac{\mathrm{a}_{\mathrm{g}}\left(\mathrm{x}_{\mathrm{i}}\right)}{2 \mathrm{~h}}\right)$

$+\widetilde{\mathrm{B}}_{\mathrm{j}}^{\prime \prime}\left(\mathrm{x}_{\mathrm{i}+2}\right)\left(\frac{\mathrm{a}_{0}\left(\mathrm{x}_{\mathrm{i}}\right)}{\mathrm{h}^{4}}+\frac{\mathrm{a}_{1}\left(\mathrm{x}_{\mathrm{i}}\right)}{2 \mathrm{~h}^{\mathrm{a}}}\right)+\widetilde{\mathrm{B}}_{\mathrm{j}}^{\prime \prime}\left(\mathrm{x}_{\mathrm{i}}\right) \mathrm{a}_{4}\left(\mathrm{x}_{\mathrm{i}}\right)+\widetilde{\mathrm{B}}_{\mathrm{j}}^{\prime}\left(\mathrm{x}_{\mathrm{i}}\right) \mathrm{a}_{\mathrm{5}}\left(\mathrm{x}_{\mathrm{i}}\right)+\widetilde{\mathrm{B}}_{\mathrm{j}}\left(\mathrm{x}_{\mathrm{i}}\right) \mathrm{a}_{6}\left(\mathrm{x}_{\mathrm{i}}\right)$

for $\mathrm{i}=2,3, \ldots, \mathrm{n}-2, \quad \mathrm{j}=2,3, \ldots, \mathrm{n}-2$.

$\mathrm{B}=\left[\mathrm{b}_{\mathrm{i}}\right]$

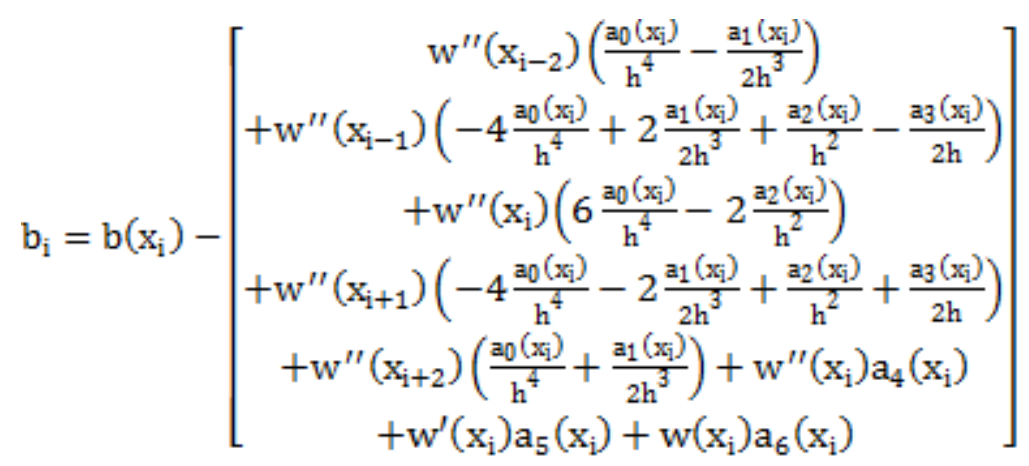

for $i=2,3, \ldots, n-2$.

and $\quad \alpha=\left[\alpha_{2}, \alpha_{3,}, \alpha_{n-2}\right]^{T}$.

\section{Solution Procedure to Find the Nodal Parameters}

The basis function $\widetilde{\mathrm{B}_{1}}(\mathrm{x})$ is defined only in the interval $\left[\mathrm{x}_{\mathrm{i}-2}, \mathrm{x}_{\mathrm{i}+2}\right]$ and outside of this interval it is zero. Also at the end points of the interval $\left[\mathrm{x}_{\mathrm{i}-2}, \mathrm{x}_{\mathrm{i}+2}\right]$ the basis function $\widetilde{\mathrm{B}_{1}}(\mathrm{x})$ vanishes. Therefore, $\widetilde{\mathrm{B}_{1}}(\mathrm{x})$ is having non-vanishing values at the mesh points $\mathrm{x}_{\mathrm{i}-1}, \mathrm{x}_{\mathrm{i}_{e}} \mathrm{x}_{\mathrm{i}+1}$ and zero at the other mesh points. The first two derivatives of $\widetilde{\mathrm{B}_{1}}(\mathrm{x})$ also have the same nature at the mesh points as in the case of $\widetilde{\mathrm{B}_{1}}(\mathrm{x})$. Using these facts, we can say that the matrix A defined in (18) is a seven band matrix. Therefore, the system of equations (17) is a seven band system in $\alpha_{i}^{\prime}$ s. The nodal parameters $\alpha^{\prime}{ }_{1} \mathrm{~s}$ 
can be obtained by using band matrix solution package. We have used the FORTRAN-90 programming to solve the boundary value problem (1) $-(2)$ by the proposed method.

\section{NUMERICAL EXAMPLES}

To demonstrate the applicability of the proposed method for solving the sixth order boundary value problems of type(1) - (2), we considered eleven examples of which six are linear and five are non linear boundary value problems. Numerical results for each problem are presented in tabular forms and compared with the exact solutions available in the literature.

Example 1 Consider the linear boundary value problem

$y^{(6)}+x y=-\left(24+11 x+x^{3}\right) \mathrm{e}^{x}, \quad 0<x<1$

subject to the boundary conditions $y(0)=0, y(1)=0$,

$\mathrm{y}^{\prime}(0)=1, \mathrm{y}^{\prime}(1)=-\mathrm{e}, \mathrm{y}^{n}(0)=0, \mathrm{y}^{\prime \prime}(1)=-4 \mathrm{e}$.

The exact solution for the above problem is given by $\mathrm{y}(\mathrm{x})=\mathrm{x}(1-\mathrm{x}) \mathrm{e}^{\mathrm{x}}$. The proposed method is tested on this problem where the domain $[0,1]$ is divided into 10 equal subintervals. Numerical results for this problem are shown in Table 1. The maximum absolute error obtained by the proposed method is $7.145405 \times 10^{-4}$.

Table 1. Numerical results for Example 1

\begin{tabular}{|c|c|c|}
\hline $\mathrm{x}$ & Exact Solution & Absolute error by proposed method \\
\hline 0.1 & $9.946539 \mathrm{E}-02$ & $3.838539 \mathrm{E}-05$ \\
\hline 0.2 & $1.954244 \mathrm{E}-01$ & $1.605898 \mathrm{E}-04$ \\
\hline 0.3 & $2.834704 \mathrm{E}-01$ & $3.449917 \mathrm{E}-04$ \\
\hline 0.4 & $3.580379 \mathrm{E}-01$ & $5.393624 \mathrm{E}-04$ \\
\hline 0.5 & $4.121803 \mathrm{E}-01$ & $6.807446 \mathrm{E}-04$ \\
\hline 0.6 & $4.373085 \mathrm{E}-01$ & $7.145405 \mathrm{E}-04$ \\
\hline 0.7 & $4.228881 \mathrm{E}-01$ & $6.124675 \mathrm{E}-04$ \\
\hline 0.8 & $3.560865 \mathrm{E}-01$ & $3.925562 \mathrm{E}-04$ \\
\hline 0.9 & $2.213642 \mathrm{E}-01$ & $1.347959 \mathrm{E}-04$ \\
\hline
\end{tabular}

Example 2 Consider the linear boundary value problem

$y^{(6)}+y=6 \cos x, \quad 0<x<1$

subject to the boundary conditions

$y(0)=0, y(1)=0, y^{\prime}(0)=-1, y^{\prime}(1)=\sin 1, y^{\prime \prime}(0)=2, y^{\prime \prime}(1)=2 \cos 1$.

The exact solution for the above problem is given by $y(x)=(x-1) \sin x$. The proposed method is tested on this problem where the domain $[0,1]$ is divided into 10 equal subintervals. Numerical results for this problem are shown in Table 2 . The maximum absolute error obtained by the proposed method is $7.493794 \times 10^{-5}$.

Table 2. Numerical results for Example 2

\begin{tabular}{|c|c|c|}
\hline $\mathrm{x}$ & Exact Solution & Absolute error by proposed method \\
\hline 0.1 & $-8.985008 \mathrm{E}-02$ & $1.292676 \mathrm{E}-05$ \\
\hline 0.2 & $-1.589355 \mathrm{E}-01$ & $3.780425 \mathrm{E}-05$ \\
\hline 0.3 & $-2.068641 \mathrm{E}-01$ & $6.052852 \mathrm{E}-05$ \\
\hline 0.4 & $-2.336510 \mathrm{E}-01$ & $7.376075 \mathrm{E}-05$ \\
\hline 0.5 & $-2.397128 \mathrm{E}-01$ & $7.493794 \mathrm{E}-05$ \\
\hline 0.6 & $-2.258570 \mathrm{E}-01$ & $6.490946 \mathrm{E}-05$ \\
\hline 0.7 & $-1.932653 \mathrm{E}-01$ & $4.705787 \mathrm{E}-05$ \\
\hline 0.8 & $-1.434712 \mathrm{E}-01$ & $2.594292 \mathrm{E}-05$ \\
\hline 0.9 & $-7.833266 \mathrm{E}-02$ & $7.897615 \mathrm{E}-06$ \\
\hline
\end{tabular}


Cubic B-Spline Collocation Method for Sixth Order Boundary Value Problems

Example 3 Consider the linear boundary value problem

$y^{(6)}+y^{m \prime}+y^{n}-y=e^{-x}\left(-15 x^{2}+78 x-114\right), \quad 0<x<1$

subject to the boundary conditions

$y(0)=0, y(1)=\frac{1}{e}, y^{\prime}(0)=0, y^{\prime}(1)=\frac{2}{e}, y^{\prime \prime}(0)=0, y^{\prime \prime}(1)=\frac{1}{e}$

The exact solution for the above problem is given by $y(x)=x^{3} e^{-x}$. The proposed method is tested on this problem where the domain $[0,1]$ is divided into 10 equal subintervals. Numerical results for this problem are shown in Table 3. The maximum absolute error obtained by the proposed method is $3.400743 \times 10^{-4}$.

Table 3. Numerical results for Example 3

\begin{tabular}{|c|c|c|}
\hline $\mathrm{x}$ & Exact Solution & Absolute error by proposed method \\
\hline 0.1 & $9.048374 \mathrm{E}-04$ & $7.153023 \mathrm{E}-05$ \\
\hline 0.2 & $6.549846 \mathrm{E}-03$ & $2.032770 \mathrm{E}-04$ \\
\hline 0.3 & $2.000210 \mathrm{E}-02$ & $3.059022 \mathrm{E}-04$ \\
\hline 0.4 & $4.290048 \mathrm{E}-02$ & $3.400743 \mathrm{E}-04$ \\
\hline 0.5 & $7.581633 \mathrm{E}-02$ & $3.038347 \mathrm{E}-04$ \\
\hline 0.6 & $1.185433 \mathrm{E}-01$ & $2.197921 \mathrm{E}-04$ \\
\hline 0.7 & $1.703288 \mathrm{E}-01$ & $1.220554 \mathrm{E}-04$ \\
\hline 0.8 & $2.300564 \mathrm{E}-01$ & $4.425645 \mathrm{E}-05$ \\
\hline 0.9 & $2.963893 \mathrm{E}-01$ & $5.662441 \mathrm{E}-06$ \\
\hline
\end{tabular}

Example 4 Consider the linear boundary value problem

$y^{(6)}+y^{(5)}=-2 \mathrm{e}^{\mathrm{x}}, \quad 0<x<1$

subject to the boundary conditions

$y(0)=-1, y(1)=2-e$

$\mathrm{y}^{\prime}(0)=1, \mathrm{y}^{\prime}(1)=2-\mathrm{e}$,

$\mathrm{y}^{n}(0)=-1, \mathrm{y}^{n}(1)=-\mathrm{e}$,

The exact solution for the above problem is given by $y(x)=2 x-e^{-x}$. The proposed method is tested on this problem where the domain $[0,1]$ is divided into 10 equal subintervals. Numerical results for this problem are shown in Table 4. The maximum absolute error obtained by the proposed method is $6.151199 \times 10^{-5}$

Table 4. Numerical results for Example 4

\begin{tabular}{|c|c|c|}
\hline $\mathrm{x}$ & Exact Solution & Absolute error by proposed method \\
\hline 0.1 & $-9.051709 \mathrm{E}-01$ & $4.231930 \mathrm{E}-06$ \\
\hline 0.2 & $-8.214027 \mathrm{E}-01$ & $1.662970 \mathrm{E}-05$ \\
\hline 0.3 & $-7.498588 \mathrm{E}-01$ & $3.403425 \mathrm{E}-05$ \\
\hline 0.4 & $-6.918247 \mathrm{E}-01$ & $5.102158 \mathrm{E}-05$ \\
\hline 0.5 & $-6.487213 \mathrm{E}-01$ & $6.151199 \mathrm{E}-05$ \\
\hline 0.6 & $-6.221188 \mathrm{E}-01$ & $6.097555 \mathrm{E}-05$ \\
\hline 0.7 & $-6.137527 \mathrm{E}-01$ & $4.911423 \mathrm{E}-05$ \\
\hline 0.8 & $-6.255409 \mathrm{E}-01$ & $2.896786 \mathrm{E}-05$ \\
\hline 0.9 & $-6.596031 \mathrm{E}-01$ & $9.059906 \mathrm{E}-06$ \\
\hline
\end{tabular}

Example 5 Consider the linear boundary value problem

$y^{(6)}-y=-6 \mathrm{e}^{\mathrm{x}}, \quad 0<x<1$ 
Cubic B-Spline Collocation Method for Sixth Order Boundary Value Problems

subject to the boundary conditions $y(0)=1, y(1)=0, y^{\prime}(0)=0, y^{\prime}(1)=-e$,

$y^{\prime \prime}(0)=-1, y^{n}(1)=-2 \mathrm{e}$.

The exact solution for the above problem is given by $y(x)=(1-x) e^{x}$. The proposed method is tested on this problem where the domain $[0,1]$ is divided into 10 equal subintervals. Numerical results for this problem are shown in Table 5 . The maximum absolute error obtained by the proposed method is $1.838207 \times 10^{-4}$.

Table 5. Numerical results for Example 5

\begin{tabular}{|c|c|c|}
\hline $\mathrm{x}$ & Exact Solution & Absolute error by proposed method \\
\hline 0.1 & $9.946538 \mathrm{E}-01$ & $1.263618 \mathrm{E}-05$ \\
\hline 0.2 & $9.771222 \mathrm{E}-01$ & $4.839897 \mathrm{E}-05$ \\
\hline 0.3 & $9.449012 \mathrm{E}-01$ & $9.769201 \mathrm{E}-05$ \\
\hline 0.4 & $8.950948 \mathrm{E}-01$ & $1.460910 \mathrm{E}-04$ \\
\hline 0.5 & $8.243606 \mathrm{E}-01$ & $1.787543 \mathrm{E}-04$ \\
\hline 0.6 & $7.288475 \mathrm{E}-01$ & $1.838207 \mathrm{E}-04$ \\
\hline 0.7 & $6.041259 \mathrm{E}-01$ & $1.553297 \mathrm{E}-04$ \\
\hline 0.8 & $4.451082 \mathrm{E}-01$ & $9.888411 \mathrm{E}-05$ \\
\hline 0.9 & $2.459602 \mathrm{E}-01$ & $3.394485 \mathrm{E}-05$ \\
\hline
\end{tabular}

Example 6 Consider the linear boundary value problem

$15 \mathrm{x}(1-\mathrm{x}) \mathrm{y}^{(6)}+\mathrm{xy}^{(5)}+\left(25+\mathrm{e}^{2 \mathrm{x}}\right) \mathrm{y}^{(4)}+\left(5+\mathrm{e}^{\mathrm{x}}\right) \mathrm{y}^{\prime \prime}+\mathrm{xy}=\pi^{2} \cos (\pi \mathrm{x}) \mathrm{x}$
$+\left(-\left(5+\mathrm{e}^{\mathrm{x}}\right) \pi^{2}+\left(25+\mathrm{e}^{2 \mathrm{x}}\right) \pi^{4}+\mathrm{x}+15 \pi^{6}(\mathrm{x}-1) \mathrm{x}\right) \sin (\pi \mathrm{x}), 0<x<1$

subject to the boundary conditions

$y(0)=0, y(1)=0$,

$y^{\prime}(0)=\pi, y^{\prime}(1)=-\pi$,

$y^{\prime \prime}(0)=0, y^{n}(1)=0$.

The exact solution for the above problem is given by $y(x)=\sin (\pi x)$. The proposed method is tested on this problem where the domain $[0,1]$ is divided into 10 equal subintervals. Numerical results for this problem are shown in Table 6 . The maximum absolute error obtained by the proposed method is $1.010895 \times 10^{-4}$.

Table 6. Numerical results for Example 6

\begin{tabular}{|c|c|c|}
\hline $\mathrm{x}$ & Exact Solution & Absolute error by proposed method \\
\hline 0.08 & $2.486899 \mathrm{E}-01$ & $1.572073 \mathrm{E}-05$ \\
\hline 0.24 & $6.845471 \mathrm{E}-01$ & $5.888939 \mathrm{E}-05$ \\
\hline 0.40 & $9.510565 \mathrm{E}-01$ & $1.010895 \mathrm{E}-04$ \\
\hline 0.56 & $9.822872 \mathrm{E}-01$ & $2.437830 \mathrm{E}-05$ \\
\hline 0.72 & $7.705132 \mathrm{E}-01$ & $2.980232 \mathrm{E}-06$ \\
\hline 0.88 & $3.681246 \mathrm{E}-01$ & $5.602837 \mathrm{E}-06$ \\
\hline 0.96 & $1.253333 \mathrm{E}-01$ & $2.145767 \mathrm{E}-06$ \\
\hline
\end{tabular}

Example 7 Consider the nonlinear boundary value problem

$y^{(6)}-20 \mathrm{e}^{-36 y(x)}=$

$-40(1+x)^{-6}, \quad 0<x<1$

subject to the boundary conditions 
Cubic B-Spline Collocation Method for Sixth Order Boundary Value Problems

$y(0)=0, y(1)=\frac{1}{6} \ln 2, y^{\prime}(0)=\frac{1}{6}, y^{\prime}(1)=\frac{1}{12^{\prime}}$

$y^{n}(0)=\frac{-1}{6}, y^{n}(1)=\frac{-1}{24}$

The exact solution for the above problem is given by $y(x)=\frac{1}{6} \ln (1+x)$. This nonlinear boundary value problem is converted into a sequence of linear boundary value problems generated by quasilinearization technique $[20]$ as

$y_{(n+1)}^{(6)}+\left[720 e^{-36 y(n)}\right] y_{(n+1)}=$

$720 y_{(n)} e^{-36 y(n)}+20 e^{-36 y(n)}-40(1+x)^{-6}$, for $n=0,1,2, \ldots$

subject to the boundary conditions

$\mathrm{y}_{(\mathrm{n}+1)}(0)=0, \mathrm{y}_{(\mathrm{n}+1)}(1)=\frac{1}{6} \ln 2 \mathrm{y}_{(\mathrm{n}+1)}^{z}(0)=\frac{1}{6}, \mathrm{y}_{(\mathrm{n}+1)}^{z}(1)=\frac{1}{12^{\prime}}$

$y_{(\mathrm{n}+1)}^{n \prime}(0)=\frac{-1}{6}, y_{(\mathrm{n}+1)}^{n}(1)=\frac{-1}{24}$.

Here $y_{(n+1)}$ is the $(n+1)^{\text {th }}$ approximation for $y$. The domain $[0,1]$ is divided into 10 equal subintervals and the proposed method is applied to the sequence of problems [34]. Numerical results for this problem are presented in Table 7. The maximum absolute error obtained by the proposed method is $1.660734 \times 10^{-5}$.

Table 7. Numerical results for Example 7

\begin{tabular}{|c|c|c|}
\hline $\mathrm{x}$ & Exact Solution & Absolute error by proposed method \\
\hline 0.1 & $1.588503 \mathrm{E}-02$ & $2.993271 \mathrm{E}-06$ \\
\hline 0.2 & $3.038693 \mathrm{E}-02$ & $8.992851 \mathrm{E}-06$ \\
\hline 0.3 & $4.372738 \mathrm{E}-02$ & $1.421943 \mathrm{E}-05$ \\
\hline 0.4 & $5.607871 \mathrm{E}-02$ & $1.660734 \mathrm{E}-05$ \\
\hline 0.5 & $6.757752 \mathrm{E}-02$ & $1.563877 \mathrm{E}-05$ \\
\hline 0.6 & $7.833394 \mathrm{E}-02$ & $1.204014 \mathrm{E}-05$ \\
\hline 0.7 & $8.843804 \mathrm{E}-02$ & $7.197261 \mathrm{E}-06$ \\
\hline 0.8 & $9.796445 \mathrm{E}-02$ & $2.980232 \mathrm{E}-06$ \\
\hline 0.9 & $1.069757 \mathrm{E}-01$ & $5.215406 \mathrm{E}-07$ \\
\hline
\end{tabular}

Example 8 Consider the nonlinear boundary value problem

$y^{(6)}+\mathrm{e}^{-\mathrm{x}} \mathrm{y}^{2}=\mathrm{e}^{-\mathrm{x}}+\mathrm{e}^{-3 \mathrm{x}}, \quad 0<x<1$

subject to the boundary conditions

$y(0)=1, y(1)=\frac{1}{e^{y}}$

$y^{\prime}(0)=-1, y^{\prime}(1)=\frac{-1}{e}$

$\mathrm{y}^{\prime \prime}(0)=1, \mathrm{y}^{n}(1)=\frac{1}{e^{*}}$

The exact solution for the above problem is given by $y(x)=e^{-x}$. This nonlinear boundary value problem is converted into a sequence of linear boundary value problems generated by quasilinearization technique [20] as

$y_{(n+1)}^{(6)}+\left[2 e^{-x_{y}} y_{(n)}\right] y_{(n+1)}=e^{-x^{2}}{ }_{(n)}+e^{-x}+e^{-3 x}$, for $n=0,1,2, \ldots$

subject to the boundary conditions

$\mathrm{y}_{(\mathrm{n}+1)}(0)=1, \mathrm{y}_{(\mathrm{n}+1)}(1)=\frac{1}{e^{x}}$

$\mathrm{y}_{(\mathrm{n}+1)}^{\prime}(0)=-1, \mathrm{y}_{(\mathrm{n}+1)}^{\prime}(1)=\frac{-1}{\mathrm{e}^{\prime}}$ 
Cubic B-Spline Collocation Method for Sixth Order Boundary Value Problems

$\mathrm{y}_{(\mathrm{n}+1)}^{n}(0)=1, \mathrm{y}_{(\mathrm{n}+1)}^{n}(1)=\frac{1}{\mathrm{e}}$.

Here $y_{(n+1)}$ is the $(n+1)^{\text {th }}$ approximation for $y$. The domain $[0,1]$ is divided into 10 equal subintervals and the proposed method is applied to the sequence of problems [38]. Numerical results for this problem are presented in Table 8. The maximum absolute error obtained by the proposed method is $5.125999 \times 10^{-6}$.

Table 8. Numerical results for Example 8

\begin{tabular}{|c|c|c|}
\hline $\mathrm{x}$ & Exact Solution & Absolute error by proposed method \\
\hline 0.1 & $9.048374 \mathrm{E}-01$ & $2.443790 \mathrm{E}-06$ \\
\hline 0.2 & $8.187308 \mathrm{E}-01$ & $5.006790 \mathrm{E}-06$ \\
\hline 0.3 & $7.408182 \mathrm{E}-01$ & $5.125999 \mathrm{E}-06$ \\
\hline 0.4 & $6.703200 \mathrm{E}-01$ & $3.755093 \mathrm{E}-06$ \\
\hline 0.5 & $6.065307 \mathrm{E}-01$ & $2.563000 \mathrm{E}-06$ \\
\hline 0.6 & $5.488116 \mathrm{E}-01$ & $2.264977 \mathrm{E}-06$ \\
\hline 0.7 & $4.965853 \mathrm{E}-01$ & $2.741814 \mathrm{E}-06$ \\
\hline 0.8 & $4.493290 \mathrm{E}-01$ & $2.354383 \mathrm{E}-06$ \\
\hline 0.9 & $4.065697 \mathrm{E}-01$ & $1.102686 \mathrm{E}-06$ \\
\hline
\end{tabular}

Example 9 Consider the nonlinear boundary value problem

$y^{(6)}=\mathrm{e}^{\mathrm{x}} \mathrm{y}^{3}(\mathrm{x}), \quad 0<x<1$

subject to the boundary conditions

$y(0)=1, y(1)=e^{\frac{-1}{2}}$,

$y^{\prime}(0)=\frac{-1}{2}, y^{\prime}(1)=\frac{-1}{2} \mathrm{e}^{\frac{-1}{2}}$,

$\mathrm{y}^{\prime \prime}(0)=\frac{1}{4}, \mathrm{y}^{n}(1)=\frac{1}{4} \mathrm{e}^{\frac{-1}{x}}$.

This nonlinear boundary value problem is converted into a sequence of linear boundary value problems generated by quasi-linearization technique $[20]$ as

$y_{(n+1)}^{(6)}+\left[-3 e^{x} y_{(n)}^{2}\right] y_{(n+1)}=-2 e^{x} y_{(n)}^{3} \quad$ for $n=0,1,2, \ldots$

subject to the boundary conditions

$y_{(n+1)}(0)=1, y_{(n+1)}(1)=e^{\frac{-1}{2}}, y_{(n+1)}^{\prime}(0)=\frac{-1}{2}, y_{(n+1)}^{\prime}(1)=\frac{-1}{2} e^{\frac{-1}{x}}$,

$\mathrm{y}_{(\mathrm{n}+1)}^{\prime \prime}(0)=\frac{1}{4}, \mathrm{y}_{(\mathrm{n}+1)}^{n \prime}(1)=\frac{1}{4} \mathrm{e}^{\frac{-1}{2}}$.

Here $y_{(n+1)}$ is the $(n+1)^{\text {th }}$ approximation for $y$. The domain $[0,1]$ is divided into 10 equal subintervals and the proposed method is applied to the sequence of problems [42]. Numerical results for this problem obtained by Hussin and Kilicman [26] and obtained by present method are presented in Table 9. The maximum absolute error obtained by the proposed method when compared with the solutions obtained by Hussin and Kilicman [26] is $3.993511 \times 10^{-6}$.

Table 9. Numerical results for Example 9

\begin{tabular}{|c|c|c|}
\hline $\mathrm{x}$ & Numerical Solution[26] & Absolute error by proposed method \\
\hline 0.1 & $9.512295 \mathrm{E}-01$ & $1.192093 \mathrm{E}-07$ \\
\hline 0.2 & $9.048374 \mathrm{E}-01$ & $3.576279 \mathrm{E}-07$ \\
\hline 0.3 & $8.607080 \mathrm{E}-01$ & $1.132488 \mathrm{E}-06$ \\
\hline 0.4 & $8.187308 \mathrm{E}-01$ & $2.503395 \mathrm{E}-06$ \\
\hline 0.5 & $7.788008 \mathrm{E}-01$ & $3.874302 \mathrm{E}-06$ \\
\hline 0.6 & $7.408182 \mathrm{E}-01$ & $3.993511 \mathrm{E}-06$ \\
\hline 0.7 & $7.046881 \mathrm{E}-01$ & $3.457069 \mathrm{E}-06$ \\
\hline 0.8 & $6.703200 \mathrm{E}-01$ & $1.609325 \mathrm{E}-06$ \\
\hline 0.9 & $6.376281 \mathrm{E}-01$ & $3.576279 \mathrm{E}-07$ \\
\hline
\end{tabular}

International Journal of Scientific and Innovative Mathematical Research (IJSIMR)

Page 10 
Example 10 Consider the nonlinear boundary value problem

$\mathrm{y}^{(6)}=\mathrm{e}^{-2 \mathrm{x}} \mathrm{y}^{2}-\frac{1}{\mathrm{x}} \sin \left(\mathrm{y}^{\prime}\right)+\mathrm{e}^{\mathrm{y}}-\frac{1}{\mathrm{x}^{2}} \mathrm{y}^{n} \mathrm{y}^{\prime \prime \prime}+\mathrm{y}^{(4)} \mathrm{e}^{\mathrm{y}^{(5)}}+\mathrm{f}(\mathrm{x}), \quad 0<x<1$

subject to the boundary conditions

$y(0)=0, y(1)=e \sin (1), y^{\prime}(0)=1, y^{\prime}(1)=e(\sin (1)+\cos (1))$

$\mathrm{y}^{\prime \prime}(0)=2, \mathrm{y}^{\prime \prime}(1)=2 \mathrm{e} \cos (1)$.

The exact solution for the above problem is given by $y(x)=e^{x} \sin (x)$. This nonlinear boundary value problem is converted into a sequence of linear boundary value problems generated by quasilinearization technique [20] as

$y_{(\mathrm{n}+1)}^{(6)}+\left[-y_{(\mathrm{n})}^{(4)} \mathrm{e}^{y_{(\mathrm{n})}^{(5)}}\right] \mathrm{y}_{(\mathrm{n}+1)}^{(5)}+\left[-\mathrm{e}^{y_{(\mathrm{n})}^{(5)}}\right] \mathrm{y}_{(\mathrm{n}+1)}^{(4)}+\left[\frac{1}{x^{2}} y_{(\mathrm{n})}^{\prime \prime}\right] y_{(\mathrm{n}+1)}^{\prime \prime \prime}+\left[\frac{1}{x^{2}} y_{(\mathrm{n})}^{\prime \prime \prime}\right] y_{(\mathrm{n}+1)}^{\prime \prime}+$

$\left[\frac{1}{x} \cos \left(y_{(n)}^{\prime}\right)\right] y_{(n+1)}^{\prime}+\left[-2 \mathrm{e}^{-2 x} y_{(n)}-e^{y(n)}\right]_{y(n+1)}=-$

$\mathrm{y}_{(\mathrm{n})} \mathrm{e}^{\mathrm{y}(\mathrm{n})}-2 \mathrm{e}^{-2 \mathrm{x}} \mathrm{y}_{(\mathrm{n})}^{2}+\left[\frac{1}{\mathrm{x}} \cos \left(\mathrm{y}_{(\mathrm{n})}^{\prime}\right)\right] \mathrm{y}_{(\mathrm{n})}^{\prime}+\left[\frac{2}{\mathrm{x}^{2}} \mathrm{y}_{(\mathrm{n})}^{\prime \prime}\right] \mathrm{y}_{(\mathrm{n})}^{\prime \prime \prime}-\left[\mathrm{e}^{\mathrm{y}_{(\mathrm{n})}^{(5)}}\right] \mathrm{y}_{(\mathrm{n})}^{(4)}-\left[\mathrm{e}^{\mathrm{y}_{(\mathrm{n})}^{(5)}}\right] \mathrm{y}_{(\mathrm{n})}^{(4)} \mathrm{y}_{(\mathrm{n})}^{(5)}+\mathrm{y}_{(\mathrm{n})}^{(6)}$,

for $\mathrm{n}=0,1,2, \ldots$

subject to the boundary conditions

$y_{(n+1)}(0)=0, y_{(n+1)}(1)=e \sin (1)$,

$\mathrm{y}_{(\mathrm{n}+1)}^{\prime}(0)=1, \mathrm{y}_{(\mathrm{n}+1)}^{\prime}(1)=\mathrm{e}(\sin (1)+\cos (1))$

$y_{(\mathrm{n}+1)}^{n}(0)=2, \quad y_{(\mathrm{n}+1)}^{n}(1)=2 \mathrm{e} \cos (1)$.

Here $y_{(n+1)}$ is the $(n+1)^{\text {th }}$ approximation for $y$. The domain $[0,1]$ is divided into 10 equal subintervals and the proposed method is applied to the sequence of problems[46]. Numerical results for this problem are presented in Table 10. The maximum absolute error obtained by the proposed method is $3.037453 \times 10^{-4}$.

Table 10. Numerical results for Example 10

\begin{tabular}{|c|c|c|c|}
\hline $\mathrm{x}$ & Exact Solution & Absolute error by proposed method & \\
\hline 0.1 & $1.103330 \mathrm{E}-01$ & $9.641051 \mathrm{E}-06$ & \\
\hline 0.2 & $2.426553 \mathrm{E}-01$ & $6.434321 \mathrm{E}-05$ \\
\hline 0.3 & $3.989106 \mathrm{E}-01$ & $1.575351 \mathrm{E}-04$ \\
\hline 0.4 & $5.809439 \mathrm{E}-01$ & $2.508163 \mathrm{E}-04$ \\
\hline 0.5 & $7.904391 \mathrm{E}-01$ & $3.037453 \mathrm{E}-04$ \\
\hline 0.6 & 1.028846 & $2.937317 \mathrm{E}-04$ \\
\hline 0.7 & 1.297295 & $2.229214 \mathrm{E}-04$ \\
\hline 0.8 & 1.596505 & $1.223087 \mathrm{E}-04$ \\
\hline 0.9 & 1.926673 & $3.397465 \mathrm{E}-05$ \\
\hline
\end{tabular}

Example 11 Consider the nonlinear boundary value problem

$$
y^{(6)}+y^{\prime} y^{(5)}-\pi^{3} \sin (\pi x) y^{\prime \prime \prime}+\pi^{2} y^{2}=-\pi^{6} \cos (\pi x), \quad 0<x<1
$$

subject to the boundary conditions

$$
\begin{aligned}
& y(0)=1, y(1)=-1, y^{\prime}(0)=0, y^{\prime}(1)=0, \\
& y^{n}(0)=-\pi^{2}, y^{\prime \prime}(1)=\pi^{2} .
\end{aligned}
$$

The exact solution for the above problem is given by $y=\cos (\pi x)$. This nonlinear boundary value problem is converted into a sequence of linear boundary value problems generated by quasilinearization technique $[20]$ as 


$$
\begin{aligned}
& \overline{y_{(n+1)}^{(6)}}+\left[y_{(n)}^{\prime}\right] y_{(n+1)}^{(5)}+\left[-\pi^{3} \sin (\pi x)\right] y_{(n+1)}^{\prime \prime}+\left[y_{(n)}\right] y_{(n+1)}^{\prime \prime}+\left[y_{(n)}^{(5)}\right] y_{(n+1)}^{\prime}+\left[y_{(n)}^{n}+\right. \\
& \left.2 y_{(n)} \pi^{2}\right] y_{(n+1)}=y_{(n)}^{\prime} y_{(n)}^{(5)}+y_{(n)}^{n} y_{(n)}+\pi^{2} y_{(n)}^{2}-\pi^{6} \cos (\pi x), \\
& \text { for } \mathrm{n}=0,1,2, \ldots
\end{aligned}
$$

subject to the boundary conditions

$$
\begin{aligned}
& y_{(\mathrm{n}+1)}(0)=1, \mathrm{y}_{(\mathrm{n}+1)}(1)=-1, \mathrm{y}_{(\mathrm{n}+1)}^{\prime}(0)=0, \mathrm{y}_{(\mathrm{n}+1)}^{\prime}(1)=0, \\
& \mathrm{y}_{(\mathrm{n}+1)}^{n}(0)=-\pi^{2}, \mathrm{y}_{(\mathrm{n}+1)}^{n}(1)=\pi^{2}
\end{aligned}
$$

Here $y_{(n+1)}$ is the $(n+1)^{\text {th }}$ approximation for $y$. The domain $[0,1]$ is divided into 10 equal subintervals and the proposed method is applied to the sequence of problems [50]. Numerical results for this problem are presented in Table 11. The maximum absolute error obtained by the proposed method is $9.543300 \times 10^{-4}$.

Table 11. Numerical results for Example 11

\begin{tabular}{|c|c|c|c|}
\hline $\mathrm{x}$ & Exact Solution & Absolute error by proposed method & \\
\hline 0.1 & $9.510565 \mathrm{E}-01$ & $2.896190 \mathrm{E}-04$ \\
\hline 0.2 & $8.090170 \mathrm{E}-01$ & $7.406473 \mathrm{E}-04$ \\
\hline 0.3 & $5.877852 \mathrm{E}-01$ & $9.543300 \mathrm{E}-04$ \\
\hline 0.4 & $3.090170 \mathrm{E}-01$ & $7.990897 \mathrm{E}-04$ \\
\hline 0.5 & $6.123032 \mathrm{E}-17$ & $3.512450 \mathrm{E}-04$ \\
\hline 0.6 & $-3.090171 \mathrm{E}-01$ & $1.802742 \mathrm{E}-04$ \\
\hline 0.7 & $-5.877852 \mathrm{E}-01$ & $5.472302 \mathrm{E}-04$ \\
\hline 0.8 & $-8.090170 \mathrm{E}-01$ & $5.689263 \mathrm{E}-04$ \\
\hline 0.9 & $-9.510565 \mathrm{E}-01$ & $2.640486 \mathrm{E}-04$ \\
\hline
\end{tabular}

\section{CONCLuSions}

In this paper, we have developed a collocation method with cubic B-splines as basis functions to solve sixth order boundary value problems. Here we have taken internal mesh points $\mathrm{x}_{2}, \mathrm{x}_{3}, \ldots, \mathrm{x}_{\mathrm{n}-2}$ as the selected collocation points. The cubic B-spline basis set has been redefined into a new set of basis functions which in number match with the number of selected collocation points. The proposed method is applied to solve several number of linear and non-linear problems to test the efficiency of the method. The numerical results obtained by the proposed method are in good agreement with the exact solutions or numerical solutions available in the literature. The objective of this paper is to present a simple method to solve a sixth order boundary value problem and its easiness for implementation.

\section{REFERENCES}

[1] Glatzmaier, G. A., Numerical simulations of stellar convection dynamics at the base of the convection zone, Geophys, Fluid Dynamics, 31, 137-150(1985).

[2] Toomore, J., Zahn, J.R., Latour J., and Spiegel E.A., Stellar convection theory II, single-mode study of the second convection zone in A-type stars, Astrophys. J., 207, 545-563(1976).

[3] Baldwin P., Asymptotic estimates of the eigenvalues of a sixth-order boundary-value problem obtained by using global phase-integral methods, Phil. Trans. Roy, Soc. Lond. A, 322, 281-305(1987).

[4] Chandrasekhar S., Hydrodynamics and Hydromagnetic Stability, Dover, New York(1981).

[5] Siddiqi, S.S., and Twizell E.H., Spline solutions of linear sixth-order boundary value problems, Int. J. Comput. Math., 60 , 295-304(1996).

[6] Agarwal, R.P., Boundary value problems for higher-order differential equations, World Scientific, Singapore(1986).

[7] Mohamed El-Gamel, John R. Cannon, and Ahmed I zayed, Sinc-Galerkin method for solving linear sixth order boundary value problems, Mathematics of computation, 73(247), 1325-1343 (2004).

[8] Akram, G., and Siddiqi, S.S., Solution of sixth order boundary value problem using non-polynomial spline technique, Applied Mathematics and Computation, 181, 708-720(2006). 
[9] Siddiqi S.S., Akram G., and Nazeer S., Quintic spline solution of linear sixth order boundary value problems, Applied Mathematics and Computation, 189, 887-892(2007).

[10] Siddiqi S.S., and Akram G., Septic spline solutions of sixth order boundary value problems, Journal of computational and applied Mathematics, 215, 288-301(2008).

[11] Abdellah Lamini, Hamid Mraoui, Driss Sbibih, Ahmed Tijini and Ahmed Zidna, Spline collocation method for solving linear sixth order boundary-value problems, International Journal of Computer Mathematics, 85(11), 1673-1684(2008).

[12] Wazwaz A., The numerical solution of sixth order boundary value problems by the modified decomposition method, Appl. Math. Comput. , 118, 311-325(2001).

[13] He J., Variational approach to the sixth order boundary value problems, Appl. Math. Comput. , 143, 235236(2003).

[14] Noor M.A., and Mohyud-Din S.T., Homotopy perturbation method for solving sixth-order boundary value problems, Comput Math Appl, 55, 2953-2972(2008).

[15] Noor M.A., Noor K.I., and Mohyud-Din S.T., Variational iteration method for solving sixth-order boundary value problems, Commun Nonlinear Sci Numer Simulat , 14 , 2571-2580(2009).

[16] ul Islam S., Tirmizi, I.A., Haq F., and Taseer S.K., Family of numerical methods based on non polynomial splines for solution of contact problems, Commun Nonlinear Sci Numer Simulat, 13, 1448-1460(2008).

[17] ul Islam S., Tirmizi I.A., Haq F., and Khan M.A, Non-polynomial splines approach to the solution of sixth-order boundary-value problems, Appl Math Comput, 195 (1), 270-284(2008).

[18] Kasi Viswanadham K.N.S., and Murali Krishna P., Septic B-spline collocation method for sixth order boundary value problems, ARPN Journal of Engineering and Applied Sciences,5(7),36-40(2010).

[19] Kasi Viswanadham K.N.S., and Murali Krishna P., Sextic B-spline Galerkin method for sixth order boundary value problems, International J. of Math. Sci. and Engg. Appls., 4(4), 377-387(2010).

[20] Bellman R.E., and Kalaba R.E., Quasi linearization and Nonlinear Boundary value problems, American Elsevier, New York (1965).

[21] Reddy J.N., An introduction to the Finite Element Method, Tata Mc-GrawHill Publishing Company Limited, 3rd Edition, New Delhi(2005).

[22] Prenter P.M., Splines and Variational Methods, John-Wiley and Sons, New York(1989).

[23] Cox, M.G., The numerical evaluation of B-Splines, Jour. Inst. Mathematics and Appl., Stat.,10, 134149(1972).

[24] Carl de Boor, A Practical Guide to Splines, Springer-Verlag(1978) .

[25] Schoenberg I.J., On Spline Functions, University of Wisconsin, MRC Report 625(1966).

[26] Hussin and Kilicman, The use of Adomian decomposition method for solving Nonlinear Higher-Order Boundary Value Problems, Mathematical Problems in Engineering, Article ID 724927, 19 pages(2011).

\section{AUTHOR's BIOGRAPHY}

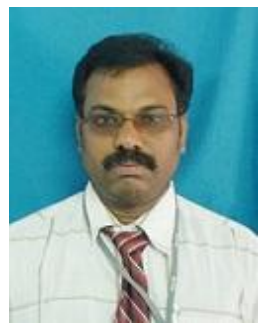

Y. Showri Raju, completed his master's degree from Pondicherry University during the academic years 1995-1997. He obtained his PhD degree from NITWarangal during the year 2014. His area of interest is Finite Element Methods. At present he is working at Department of Computational Sciences as Associate professor, Wollega University, Nekemte, Ethiopia. The author has University level experience to teach both UG and PG level courses.

Citation: Y. S. Raju, " Cubic B-Spline Collocation Method for Sixth Order Boundary Value Problems ", International Journal of Scientific and Innovative Mathematical Research, vol. 5, no. 7, p. 1-13, 2017., http://dx.doi.org/10.20431/2347-3142.0507001

Copyright: () 2017 Authors. This is an open-access article distributed under the terms of the Creative Commons Attribution License, which permits unrestricted use, distribution, and reproduction in any medium, provided the original author and source are credited. 